\title{
PERMANÊNCIA NA UNIVERSIDADE: O QUE DIZEM OS ESTUDANTES INDÍGENAS DA UNIVERSIDADE ESTADUAL DO CENTRO-OESTE DO PARANÁ
}

\author{
J. S. ANGNES ${ }^{1 *}$, M. F. Q. FREITAS ${ }^{2}$, M. L. KLOZOVSKI ${ }^{1}$, S. M. M. MATTOS ${ }^{1}$ e Z. F. COSTA ${ }^{1}$ \\ ${ }^{1}$ Universidade Estadual do Centro-Oeste do Paraná - UNICENTRO \\ ${ }^{2}$ Universidade Federal do Paraná - UFPR \\ julianeangnes@gmail.com *
}

Artigo submetido em setembro/2013 e aceito em dezembro/2014

DOI: $10.15628 /$ holos.2014.1658

\section{RESUMO}

Este artigo analisa questões que dificultam/dificultaram a permanência dos estudantes indígenas na Universidade Estadual do Centro Oeste do Paraná (UNICENTRO), a partir do Vestibular Específico para Povos Indígenas neste estado. Trata-se de uma pesquisa qualitativa, realizada com recorte temporal de 2002 a 2010, que teve como eixo norteador à busca da compreensão dos sentidos que perpassam as enunciações dos índios na UNICENTRO. Na busca da compreensão desses sentidos, as vozes (e silêncio) dos indígenas foram trazidas para a reflexão. Percebeu-se que as dificuldades de adaptação aliadas a pouca visibilidade política de que estes grupos se revestem junto à comunidade acadêmica, são alguns dos fatores motivadores a desistência destes na UNICENTRO.

PALAVRAS-CHAVE: Permanência na Universidade. Desistência na Universidade. Relações Sociais. Estudantes Indígenas.

\section{STAYING IN THE UNIVERSITY: WHAT DO SAY INDIGENOUS STUDENTS AT THE UNIVERSIDADE ESTADUAL DO CENTRO-OESTE DO PARANÁ}

\begin{abstract}
This article examines issues that hinder/hindered the retention of indigenous students at the Universidade Estadual do Centro Oeste do Paraná (UNICENTRO) from the vestibular specific to indigenous peoples in this state. This is a qualitative research conducted with time frame from 2002 to 2010, which had as its guiding principle the pursuit of understanding the meanings that
\end{abstract}

underlie the utterances of indians in UNICENTRO. In search of understanding these senses, the voices (and silence) of the indigenous people were brought to the debate. It was felt that the difficulties of adaptation to low visibility political allies of these groups lining up in the academic community are some of the motivating factors in the cancellation of these UNICENTRO.

KEYWORDS: Staying at the University. Withdrawal University. Social Relations. Indigenous Students. 


\section{INTRODUÇÃO}

A trajetória sócio-histórica para qualquer estudante, que almeje conquistar um diferencial competitivo para sua entrada no mercado de trabalho encontra-se vinculada ao ingresso no Ensino Superior. Para o estudante indígena, este caminho poderia parecer simples, em um primeiro momento, em razão do novo paradigma da educação indígena que privilegia a diversidade cultural. Entretanto, à medida que, os índios avançam em direção à consecução dos seus próprios projetos de conquista esbarram com duas questões: o ingresso na educação de nível superior e a permanência/conclusão nas universidades.

Segundo estimativas da Fundação Nacional do índio (2007), mais de 2000 estudantes indígenas tiveram acesso às universidades brasileiras, por meio das ações afirmativas ${ }^{1}$ que giram em torno da política de cotas nas universidades brasileiras. No Brasil, cotas de participação já existem em diversos segmentos da sociedade como as cotas eleitorais, reserva de vagas em concursos públicos para negros, pardos ou portadores de necessidades especiais.

As primeiras iniciativas direcionadas especificamente à oferta de vagas para indígenas em cursos regulares partiram das Universidades Estaduais do Paraná, seguidas pela Universidade Estadual do Mato Grosso do Sul (UEMS). No que diz respeito aos indígenas, segundo dados da Fundação Nacional de Saúde Indígena (FUNASA), em 2008 o Brasil apresentava 220 etnias diferentes e tal heterogeneidade não parece ter sido contemplada pelas políticas de ação afirmativa propostas.

Na maioria das vezes, os indígenas devem enquadrar-se às políticas voltadas para "afrodescendentes" ou "carentes". Um aspecto relevante refere-se ao tipo de processo seletivo: em alguns casos, dá-se por um vestibular específico que é realizado apenas por e para indígenas, fato que não se observa em outros tipos de ação afirmativa (para negros ou estudantes de escolas públicas), sempre vinculadas ao vestibular geral (NOVAK, 2007).

Nas Universidades Estaduais do Paraná, o processo de seleção dos estudantes indígenas ocorre por meio de vestibular específico desde 2001 (Lei $\mathrm{n}$ - 13.134), levando as seis universidades estaduais públicas do Estado do Paraná a realizarem todos os anos o vestibular especial para as comunidades indígenas paranaenses. Ou seja, as vagas ofertadas são suplementares às vagas oficiais. Tal processo apresentou-se como um projeto de estado inovador para o Ensino Superior Indígena.

Em contraponto, na prática o maior acesso às universidades pelos povos indígenas paranaenses, trouxe à tona, desafios e dificuldades com que se defrontam essas Instituições de Ensino, sobretudo em termos de infraestrutura, que tornou mais complexa a relação dos cursos que têm em sua grade curricular aulas práticas, e que necessitam de laboratórios maiores para acomodar alunos extras.

Outra problemática recorrente no Paraná é a evasão destes alunos. De acordo com Novak (2007) os menores índices de evasão encontram-se nas universidades de Londrina, Maringá e na

1 Ações afirmativas são políticas públicas ou privadas de combate à desigualdade estrutural de grupos mais vulneráveis à discriminação. O termo surgiu nos Estados Unidos, na década de 1960, como forma de garantir direitos a grupos historicamente excluídos de sua cidadania plena (MOEHLECKE, 2004). Sendo assim, a "Ação Afirmativa" é uma política da qual o sistema de cotas faz parte. 
Universidade Federal do Paraná (UFPR). Este fato pode estar relacionado à implantação, por parte dessas Universidades, de políticas de acompanhamento para os acadêmicos indígenas.

De certa forma, isso leva a crer, que nas outras Universidades Estaduais ${ }^{2}$, nas quais o número de desistências é elevado, a solução estaria na constituição e implantação de políticas mais sólidas de permanência para esses acadêmicos indígenas. Ou seja, observa-se que a existência de um único "Vestibular dos Povos Indígenas do Paraná" não corresponde aos mesmos recursos para a permanência e conclusão dos ingressos em cada instituição. (AMARAL, 2010)

Contudo, acredita-se que as dificuldades de permanência indígena no Ensino Superior, envolvem uma trajetória que passa por outras questões que não sejam apenas estruturais, mas de ordem psicossocial desses estudantes, e, que devem ser investigadas para que se possam compreender os fenômenos sociais e culturais implícitos neste processo de abandono e de tentativas de educação inclusiva.

Trabalhar com a diversidade cultural não é um processo simples. Observa-se, que docentes se deparam a todo instante no contexto universitário com situações de aprendizagem e de relacionamento que não sabem como trabalhar. Com os estudantes indígenas esse processo não é diferente. Não há curso ou treinamento que ensine o professor a trabalhar com uma cultura diferenciada da sua, principalmente com as populações indígenas, que possuem um contexto de socialização totalmente diferenciado da cultura "branca-ocidental". O "diferente causa estranhamento" como afirmou Goffmann (1988, p. 16).

Neste sentido, a realização desta pesquisa adotou como pressuposto a necessidade de saber transitar na esfera da cultura indígena, de forma que pudesse apresentar para a Universidade Estadual do Centro-Oeste do Paraná um panorama sobre a permanência e desistência dos estudantes indígenas que optam por esta universidade. Ou seja, desde o ano de 2002, as vagas destinadas a representantes indígenas são preenchidas pelo vestibular específico, porém os estudantes apenas ingressam na Universidade e não permanecem na mesma. Assim, a questão problemática delimitada para este estudo foi: Quais os fatores que dificultam/dificultaram a permanência dos estudantes indígenas na universidade?

Desta forma, o objetivo geral visou analisar questões que dificultam/dificultaram a permanência dos estudantes indígenas na Universidade Estadual do Centro Oeste do Paraná (UNICENTRO), considerando a experiência do Vestibular Específico para Povos Indígenas neste estado. Cabe destacar, que o estudo realizado configura-se qualitativamente a partir da perspectiva dos indígenas na UNICENTRO, não pretendendo dar conta o universo total composto por estes estudantes nas outras universidades do estado do Paraná.

\section{A EDUCAÇÃO SUPERIOR PARA POVOS INDÍGENAS NO BRASIL}

Embora impere o consenso de que o princípio fundamental da luta do movimento indígena e da política indígena é o direito à diferença, e que o respeito devido a esta diferença não admite formas de discriminação no atendimento aos direitos básicos de todo cidadão e de todo grupo social, na prática, muitas ações voltadas aos índios parecem calcadas em objetivos diferentes, ou seja, buscam a igualdade dos índios aos "não índios" (D'ANGELIS, 2000).

2 Universidade Estadual de Ponta Grossa (UEPG), Universidade Estadual do Oeste do Paraná (UNIOESTE), Universidade Estadual do Centro-Oeste (UNICENTRO) e Universidade Estadual do Norte do Paraná (UENP). 
A explicação dessa atitude reside no fato de que os esforços empreendidos até aqui pelos órgãos implementadores das políticas públicas voltadas aos Índios pautaram-se muito mais na "Escola Para o Índio", do que na "Escola Do Índio". De acordo com Costa essa postura pode ser explicada:

A permanência incrustada na cabeça dos professores, da pedagogia tradicional, em partes, denuncia de certa forma a incapacidade do pensamento laico em superar a organização da cultura, forjada pelo capitalismo e a elite dominante no Brasil, originária em nosso país devido à colaboração da Educação Jesuítica, acrescida pela ferocidade com que eram caçados pelos bandeirantes paulistas. (COSTA, 2005, p. 17)

Contrária a esta posição, encontra-se a demanda por uma educação superior do indígena, que passou a ser assunto de relevância nas últimas décadas, principalmente após a Constituição de 1988, propiciando um momento de redimensionamento das relações entre índios e não índios. Dito de outra forma, com o advento da Constituição de 1988 e os avanços pósconstituição na questão indígena, fortaleceu-se o trabalho das organizações indígenas e deram condições de "reconhecimento do direito à diversidade étnica e cultural" (SILVA, 2005, p. 121).

Conforme Baniwa "esta política da FUNAI permaneceu nos anos 2000, sendo que, muitos desses estudantes passaram a ser, aos poucos, incorporados pelas universidades públicas ou pelos programas de crédito do Governo Federal" (BANIWA, 2006, p. 89). Assim, várias destas experiências ocorreram de forma isolada e fragmentada movidas pela iniciativa pessoal dos indígenas ou junto às suas famílias.

Em complemento, também nos anos 2000, iniciou-se uma nova discussão referente às políticas públicas direcionadas ao ensino superior para os povos indígenas. Essa discussão ocorreu por ocasião da comemoração dos 500 anos da presença, colonização, exploração e expropriação dos seus territórios tradicionais por não-indígenas.

Em suas pesquisas Souza Lima e Barroso-Hoffmann (2004) destacam que o ensino superior para os povos indígenas, divide-se em duas vertentes diferentes, mas historicamente entrelaçadas, que tem sido percebidas de modo separado e que, todavia, confluem na busca dos povos indígenas por uma formação no ensino superior.

Estas vertentes são classificadas da seguinte forma: a) formação superior para professores indígenas em cursos específicos (licenciaturas interculturais) e; b) formação de ensino superior em busca de outras profissões para inserção no mercado de trabalho. É nesta segunda vertente que se enquadra o Vestibular Específico para os Povos Indígenas do Paraná, ou seja, nesta perspectiva, Oliveira (1998) apresenta a formação de ensino superior devido:

A necessidade de se ter profissionais indígenas graduados nos saberes científicos veiculados pelas universidades, capazes de articular, quando cabível, esses saberes e os conhecimentos tradicionais de seus povos, pondo-se à frente da resolução de necessidades surgidas com o processo contemporâneo de territorialização a que estão submetidos e, que culminou nas demarcações de terras para as coletividades. (OLIVEIRA, 1998, p. 34)

Entretanto, mesmo o vestibular paranaense se enquadrando na vertente citada, em 2010 a Comissão Universidade para os Índios (CUIA) da UNICENTRO, diagnosticou que o número de 
desistentes chegou a um percentual de 50\%, o que se tornou um número significativo, considerando-se que a universidade localiza-se próxima as Terras Indígenas (TIS) de Rio das Cobras e Mangueirinha, aonde a maioria desses estudantes reside (PESQUISA DOCUMENTAL, 2010).

Assim, considera-se o percentual de desistência na UNICENTRO um problema sério, pois além da bolsa-auxílio ofertada, esta universidade se diferencia das outras, porque possui um programa da Tutoria Discente regulamentado pelo Conselho de Ensino, Pesquisa e Extensão (CEPE), que visa auxiliar na inclusão dos alunos pertencentes a grupos que necessitam de ações inclusivas (indígenas e deficientes visuais e auditivos).

Tudo leva a crer que o nível de desistência da UNICENTRO seja alto, porque a universidade não oferece assistência moradia, acompanhamento pedagógico, nem auxílio na compra de materiais didáticos como em outras universidades pesquisadas (UEL, UEM, UNIOESTE, UFPR). Porém, não há embasamento para se afirme isso categoricamente. Nada mais justo do que apresentar estas questões aos próprios indígenas envolvidos neste processo e ouvir deles as principais dificuldades encontradas neste ambiente.

\section{TRAJETÓRIA DA PESQUISA: CAMINHOS METODOLÓGICOS}

Esta pesquisa de caráter qualitativo apresenta como eixo norteador à compreensão dos diferentes aspectos psicossociais existentes na relação entre a universidade e o estudante indígena. Dessa forma, Martinelli (1999) propõe três pontos principais que conferem à pesquisa qualitativa significativa relevância científica: (i) o seu caráter inovador, como pesquisa que se insere na busca de significados atribuídos pelos sujeitos às suas experiências sociais; (ii) a sua dimensão política que, como construção coletiva, parte da realidade dos sujeitos e a eles retorna de forma crítica e criativa; e, iii) por ser um exercício político, uma construção coletiva, a sua realização pela via da complementaridade, não da exclusão.

Assim, de acordo com informações oferecidas pela Comissão Universidade para os Índios (CUIA) da Universidade Estadual do Centro Oeste (UNICENTRO) em 5/5/2010, ao todo no período 2002-2010, ingressaram 43 estudantes indígenas. Destes, 17 estavam regularmente matriculados no ano de 2010, 5 concluíram seus cursos e 21 desistiram da universidade. Neste sentido, a pesquisa desenvolvida contou com três etapas investigativas as quais foram divididas da seguinte forma: a) bibliográfica; b) documental e c) pesquisa de campo, sendo realizadas de maneira simultânea. A pesquisa documental pautou-se em registros arquivados na CUIA da UNICENTRO, bem como, nos Relatórios Finais dos Vestibulares específicos para povos indígenas no Paraná.

Por sua vez, na pesquisa de campo com os estudantes indígenas da UNICENTRO, empregou-se a entrevista individual em profundidade, por meio de um roteiro estruturado. Ao todo a pesquisa contemplou a realização de 23 entrevistas com estudantes indígenas no período de outubro e novembro de 2010, sendo 13 matriculados/cursando (ano de 2010), 7 desistentes e 3 formados/cursos concluídos. A duração média das entrevistas foi de uma hora e todas as falas foram gravadas e transcritas com o consentimento prévio dos entrevistados no Termo de Consentimento Livre Esclarecido ${ }^{3}$. Anotações a respeito das interações, reações, dificuldades e

3 A pesquisa realizada foi aprovada pela Comissão Nacional de Ética em Pesquisa de acordo com o Parecer no 147.2010. 
eventuais manifestações dos entrevistados foram registradas na lateral das transcrições localizando os momentos e possíveis razões das suas expressões.

Após a transcrição de todas as falas, passou-se a leitura cuidadosa e atenta dos registros escritos. O passo seguinte foi agrupar as respostas conforme os temas e assuntos que emergiram do conjunto de dados. A partir desta organização, foram elaboradas tabelas a partir das informações que possibilitassem o cruzamento dos dados (FREITAS, 1986). Em conjunto com as tabelas houve o entrecruzamento dos textos descritivos, apresentando algumas dimensões de vida destes estudantes indígenas que são relevantes para a compreensão do estudo em sua totalidade.

\section{ANÁLISE DOS RESULTADOS}

\subsection{CARACTERIZAÇÃO SOCIOECONÔMICA DOS ESTUDANTES INDÍGENAS: SUJEITOS DA PESQUISA}

Com o objetivo de apresentar a realidade dos estudantes indígenas entrevistados, caracteriza-se de maneira sintética, o registro de informações sobre a situação social e econômica dos mesmos.

Desta forma, apresentam-se a seguir os dados pertinentes a etnia, idade, sexo, campus que estuda, estado civil, profissão, curso escolhido na universidade, série e ano de ingresso. Destaca-se que os quadros foram organizados de acordo com três recortes na constituição do universo e amostra da pesquisa: a) matriculados/cursando; b) desistentes e c) formados/cursos concluídos. Os treze estudantes indígenas matriculados/cursando a UNICENTRO entrevistados foram identificados conforme Quadro 1:

QUADRO 1: IDENTIFICAÇÃO DOS ESTUDANTES INDÍGENAS MATRICULADOS/CURSANDO A UNICENTRO

\begin{tabular}{|c|c|c|c|c|c|c|c|c|c|}
\hline Ent. & Etnia & Idade & $\mathbf{S}$ & $\begin{array}{l}\text { Campus } \\
\text { Estuda }\end{array}$ & $\begin{array}{c}\text { Estado } \\
\text { Civil }\end{array}$ & Profissão & Curso Estudam & Série & $\begin{array}{l}\text { Ano } \\
\text { Ing }\end{array}$ \\
\hline E1 & Guarani & 38 & $M$ & $\begin{array}{l}\text { Laranjeiras do } \\
\text { Sul }\end{array}$ & Separado & $\begin{array}{c}\text { Funcionário } \\
\text { FUNAI }\end{array}$ & Administração & 3 & 2008 \\
\hline E2 & Guarani & 19 & $M$ & $\begin{array}{c}\text { CEDETEG } \\
\text { Guarapuava }\end{array}$ & Solteiro & Estudante & Agronomia & 2 & 2008 \\
\hline E3 & Kaingang & 19 & $M$ & $\begin{array}{c}\text { CEDETEG } \\
\text { Guarapuava }\end{array}$ & Solteiro & Estudante & $\begin{array}{c}\text { Medicina } \\
\text { Veterinária }\end{array}$ & 1 & 2009 \\
\hline E4 & Kaingang & 22 & $M$ & $\begin{array}{c}\text { CEDETEG } \\
\text { Guarapuava }\end{array}$ & Solteiro & Estudante & Enfermagem & 2 & 2006 \\
\hline E5 & Kaingang & 19 & $M$ & Chopinzinho & Solteiro & Estudante & Pedagogia & 1 & 2010 \\
\hline E6 & Kaingang & 25 & $\mathrm{~F}$ & Chopinzinho & Casada & Estudante & Pedagogia & 1 & 2010 \\
\hline E7 & Kaingang & 44 & $\mathrm{~F}$ & Chopinzinho & Solteira & Professora & Pedagogia & 3 & 2007 \\
\hline E8 & Kaingang & 52 & $M$ & Chopinzinho & Casado & Professor & Pedagogia & 1 & 2010 \\
\hline E9 & Kaingang & 19 & $M$ & $\begin{array}{c}\text { CEDETEG } \\
\text { Guarapuava }\end{array}$ & Solteiro & Estudante & Fisioterapia & 2 & 2008 \\
\hline E10 & Kaingang & 28 & $M$ & Chopinzinho & Casado & Agricultor & Pedagogia & 1 & 2010 \\
\hline
\end{tabular}




\begin{tabular}{|c|l|c|c|c|c|c|c|c|c|}
\hline E11 & Kaingang & 20 & F & $\begin{array}{c}\text { Santa Cruz } \\
\text { Guarapuava }\end{array}$ & Solteira & Estudante & Serviço Social & 2 & 2008 \\
\hline E12 & Kaingang & 24 & M & Chopinzinho & Casado & Professor & Pedagogia & 1 & 2010 \\
\hline E13 & Kaingang & 19 & F & Chopinzinho & Solteira & Estudante & Pedagogia & 1 & 2010 \\
\hline
\end{tabular}

FONTE: Dados de Pesquisa (2010)

A partir da leitura do quadro apresentado, observa-se que a faixa etária dos pesquisados varia de 19 a 52 anos, sendo que nove estão na faixa etária de 19 a 25 anos. Destes cinco são do sexo masculino e quatro são do sexo feminino. Em relação ao estado civil, sete são solteiros e dois são casados. Esse fator merece destaque, pois estes dados corroboram o que os Relatórios Finais dos Vestibulares Indígenas (2007 e 2008), trazem: que a maior proporção de ingresso, busca/permanência pela/na Universidade Estadual do Centro-Oeste (UNICENTRO)concentra-se na faixa estaria entre os 17 aos 25 anos antes do casamento. Ou seja, com o término do ensino médio há um aumento do público jovem entre as populações indígenas do Paraná que anualmente solicitam a demanda por ensino superior como forma de profissionalização dentro e fora das Terras indígenas.

Em relação aos cursos escolhidos na UNICENTRO, visualiza-se que quatro destes estudantes realizam cursos integrais: agronomia, medicina veterinária, enfermagem e fisioterapia o que os impossibilita para ao trabalho visando a sustento fora da aldeia, dependendo única e exclusivamente da bolsa institucional oferecida pelo governo do estado e do auxílio da família para cursarem a universidade.

Dos outros cinco estudantes, quatro frequentam o curso de pedagogia no período noturno na extensão universitária de Chopinzinho, ou seja, residem com as famílias na Terra Indígena de Mangueirinha e se deslocam para a universidade no período da noite. Esse aspecto facilita sua permanência na universidade, pois todos se deslocam em conjunto, não necessitando morar fora da Terra Indígena.

Paralelo a isso, todos frequentam a mesma série e o mesmo curso, o que propicia uma interação entre o grupo, fortificando as relações sociais entre ambos. Desta faixa etária, apenas uma estudante realiza um curso noturno na cidade de Guarapuava (Serviço Social) e também depende da bolsa de estudos institucional para manter-se na universidade, pois se obriga a morar fora da Terra Indígena. Por sua vez, na faixa etária dos 26 aos 52 anos, observa-se que os quatro estudantes pesquisados possuem atividades profissionais. A explicação para este fator é que os índios nesta faixa etária exercem atividades nas aldeias e visam um aperfeiçoamento para o reconhecimento dessas atividades, principalmente os que estão na área de magistério indígena.

No Quadro 1, visualiza-se ainda que dois dos quatro estudantes são professores em escola indígena. Desses estudantes três são do sexo masculino e um do sexo feminino. O que comprova a predominância do sexo masculino no acesso/ingresso na universidade. Essa predominância do sexo masculino, de acordo com pesquisas realizadas por Novak (2007) e Paulino (2008) ocorre porque as mulheres encontram maiores dificuldades em deixar os filhos e os cônjuges para cursar uma universidade. Por questões culturais, os índios casam-se cedo, geralmente por volta dos 13 ou 14 anos e também constituem família nesse período, fator esse que dificulta o acesso ao ensino formal universitário para as mulheres. Os sete estudantes indígenas desistentes da 
Universidade Estadual do Centro Oeste (UNICENTRO) entrevistados foram identificados conforme Quadro 2 a seguir:

QUADRO 2: IDENTIFICAÇÃO DOS ESTUDANTES INDÍGENAS DESISTENTES DA UNICENTRO

\begin{tabular}{|c|c|c|c|c|c|c|c|c|c|}
\hline Ent. & Etnia & Idade & S & $\begin{array}{c}\text { Campus } \\
\text { Estudavam }\end{array}$ & $\begin{array}{c}\text { Estado } \\
\text { Civil }\end{array}$ & Profissão & $\begin{array}{c}\text { Curso } \\
\text { Estudavam }\end{array}$ & $\begin{array}{c}\text { Ano } \\
\text { Ing }\end{array}$ & $\begin{array}{c}\text { Ano } \\
\text { Des }\end{array}$ \\
\hline E14 & Kaingang & 27 & $\mathrm{~F}$ & $\begin{array}{c}\text { Santa Cruz } \\
\text { Guarapuava }\end{array}$ & Solteira & Artesanato & Letras & 2005 & 2007 \\
\hline E15 & Kaingang & 36 & $\mathrm{M}$ & $\begin{array}{c}\text { Santa Cruz } \\
\text { Guarapuava }\end{array}$ & Casado & Agricultura & Jornalismo & 2006 & 2008 \\
\hline E16 & Kaingang & 35 & $\mathrm{M}$ & $\begin{array}{c}\text { Santa Cruz } \\
\text { Guarapuava }\end{array}$ & Casado & Agricultura & Administração & 2003 & 2004 \\
\hline E17 & Kaingang & 27 & $\mathrm{M}$ & $\begin{array}{c}\text { Laranjeiras do } \\
\text { Sul }\end{array}$ & Casado & Técnico \\
Adm & Administração & 2007 & 2008 \\
\hline E18 & Kaingang & 27 & $\mathrm{M}$ & $\begin{array}{c}\text { Laranjeiras do } \\
\text { Sul }\end{array}$ & Casado & Técnico & Administração & 2006 & 2006 \\
\hline E19 & Kaingang & 20 & $\mathrm{M}$ & $\begin{array}{c}\text { CEDETEG } \\
\text { Guarapuava }\end{array}$ & Solteiro & Agricultura & Fisioterapia & 2009 & 2009 \\
\hline E20 & Kaingang & 27 & $\mathrm{M}$ & $\begin{array}{r}\text { Laranjeiras do } \\
\text { Sul }\end{array}$ & Casado & $\begin{array}{c}\text { Cacique } \\
\text { Agricultura }\end{array}$ & Administração & 2005 & 2006 \\
\hline
\end{tabular}

FONTE: Dados de Pesquisa (2010)

Em relação à faixa etária dos desistentes, percebe-se que estão entre os 27 aos 36 anos, sendo seis do sexo masculino e um do sexo feminino. Novamente observa-se um índice maior de predominância do sexo masculino que complementa as pesquisas realizadas por Novak (2007) e Paulino (2008) que apresentam como fato relevante a cultura que impera nas famílias indígenas em não aceitarem que as filhas-mulheres saiam de casa para estudar na cidade e morar longe dos pais. Culturalmente os núcleos familiares indígenas impõem que as mulheres solteiras e que não têm filhos devem "ficar em casa", casar-se e continuar executando os trabalhos domésticos na própria aldeia.

O Quadro 2 também apresenta que dos sete entrevistados, cinco são casados e apenas dois são solteiros aspecto este que concorda com Capelo e Tomasino (2003) quando salientam que mesmo o público de estudantes indígenas tendo aumentado significativamente o estado civil "solteiro", o número de casados ainda permanece alto, pois é uma tradição cultural do povo indígena casar-se cedo.

Quanto às atividades profissionais, observa-se que quatro dos entrevistados são agricultores em pequenas lavouras, e destes, um por ora exerce a função de cacique da aldeia, que não é um cargo remunerado. Cabe destacar, conforme observações registradas, que o processo eleitoral nas Terras Indígenas (TIs) do Paraná, não ocorre igualmente ao formato de eleições utilizado pelos "brancos" no Brasil.

Explicando melhor: nas Tls, o cacique, quando não corresponde às solicitações comunitárias em prol da população indígena, não permanece no cargo. A comunidade reúne-se em um local comum, vários índios podem se candidatar e todos votam abertamente quem será o cacique. Assim, um cacique indígena pode estar no cargo um dia ou 20 anos, dependendo de seu 
desempenho comunitário. Também, para exercer a função de cacique de uma aldeia indígena, não existe remuneração para as atividades, sendo necessário que o índio que recebe estas atribuições tenha outra fonte de renda, que no caso em estudo refere-se à lavoura. (DIÁRIO DE CAMPO, 2010). Observa-se ainda que o Quadro 2 destaca que um desistente trabalha com artesanato e somente dois tem uma atividade profissional que apresenta renda fixa (Técnico Administrativo).

Em relação à escolha de cursos no ensino superior o quadro de desistentes demonstra que as opções perpassaram pela área das Ciências Humanas (Letras e Jornalismo) e Sociais Aplicadas (Administração) que são ofertados no período noturno, permitindo assim, aos estudantes indígenas trabalharem na cidade ou na aldeia durante o período diurno. Segundo comentários registrados durante a realização das entrevistas, vários desistentes salientaram que "na visão dos índios esses cursos são mais "fáceis" de concluir do que os cursos ofertados na área da saúde e de tecnologia" (sic), o que gera uma controvérsia entre o imaginário e a realidade. As três estudantes indígenas entrevistadas formadas/cursos concluídos na Universidade Estadual do Centro Oeste (UNICENTRO) foram identificadas conforme Quadro 3:

QUADRO 3: IDENTIFICAÇÃO DOS ESTUDANTES INDÍGENAS FORMADOS DA UNICENTRO

\begin{tabular}{|c|c|c|c|c|c|c|c|c|c|}
\hline Ent. & Etnia & Idade & S & $\begin{array}{c}\text { Campus } \\
\text { Estudavam }\end{array}$ & $\begin{array}{c}\text { Estado } \\
\text { Civil }\end{array}$ & Profissão & $\begin{array}{c}\text { Curso } \\
\text { Estudavam }\end{array}$ & $\begin{array}{c}\text { Ano } \\
\text { Ing }\end{array}$ & $\begin{array}{c}\text { Ano } \\
\text { Conc }\end{array}$ \\
\hline E21 & Kaingang & 45 & $\mathrm{~F}$ & $\begin{array}{c}\text { Santa Cruz } \\
\text { Guarapuava }\end{array}$ & Casada & $\begin{array}{c}\text { Assistente } \\
\text { Social }\end{array}$ & Serviço Social & 2004 & 2008 \\
\hline E22 & Kaingang & 39 & $\mathrm{~F}$ & $\begin{array}{c}\text { Santa Cruz } \\
\text { Guarapuava }\end{array}$ & Casada & $\begin{array}{c}\text { Assistente } \\
\text { Social }\end{array}$ & Serviço Social & 2004 & 2008 \\
\hline E23 & Kaingang & 27 & $\mathrm{~F}$ & Chopinzinho & Solteira & Professora & Pedagogia & 2003 & 2006 \\
\hline
\end{tabular}

Conforme Quadro 3, observa-se que em relação à faixa etária, todas as formadas estão acima dos 25 anos de idade, sendo duas delas casadas e uma solteira. Observa-se ainda que todas as entrevistadas trabalham em atividades em que se formaram, confirmando que o índio consegue colocação no mercado de trabalho desde que tenha oportunidade igualitária para a qualificação no ensino superior.

Por sua vez em relação ao sexo, a situação na UNICENTRO para esta categoria se inverte. Ou seja, há uma predominância do sexo feminino sobre o sexo masculino. Dos cinco formados até 2010 apenas um é do sexo masculino. Os outros quatro concluintes são do sexo feminino. Esse aspecto demonstra que as mulheres são a minoria no acesso/ingresso, mas concluem o curso superior com êxito. Outra particularidade relevante é o fato das três entrevistadas exercerem suas profissões fora da aldeia trabalhando em municípios vizinhos às Terras Indígenas (TIs) de Mangueirinha e Rio das Cobras, porém residindo nas aldeias junto com suas famílias.

\subsection{PERMANÊNCIA NA UNIVERSIDADE: O QUE DIZEM OS ESTUDANTES INDÍGENAS?}

Partindo da perspectiva apresentada por Freitas (2005), apresenta-se a sistematização das entrevistas considerando-se que ao buscar entender a vida cotidiana dos estudantes indígenas na UNICENTRO, permite-se compreender as participações e não participações nas práticas 
comunitárias, nas redes de solidariedade, nas convivências cotidianas e nos processos de conscientização (FREITAS, 2008). Dito de outra forma, ao se dar "voz ao silêncio" dos estudantes indígenas por meio de suas enunciações se permite revelar as relações cotidianas na UNICENTRO desvelando-se os dilemas e conflitos vividos, muitas vezes, de maneira solitária por estes estudantes universitários em sua rede de relações cotidianas.

Dessa forma, quando perguntados sobre como foram recebidos pela UNICENTRO (Instituição e Colegas de Turma) no primeiro dia de aula, todos os estudantes indígenas entrevistados afirmaram "terem sido bem recebidos" (sic). Em suas falas os indígenas da UNICENTRO atribuíram essa "boa recepção" a diversos fatores relacionados abaixo:

a) Idade:

Me receberam muito bem, os colegas até, no início assim pela, pela diferença de idade, eu tô um poco acima da idade da média da turma, então eu fui muito bem recepcionado, alguns até, acharam que eu nem seria cotista né (...). (grifos nossos) (E1)

b) Por parecer "estudante branco normal":

Ah, tipo assim, até uns 10 dias atrás, eu acho, eles não sabiam bem exatamente quem era..., pelo rosto não dá pra ver né quem é índio e quem não é. (grifos nossos) (E6)

Entramos na sala, todo mundo ficou quieto olhando pra gente né, filmados, e a turma não sabia o que tava acontecendo. Porque a gente era indígena... Ficaram assim né com aqueles olhares admirados. Ah, é aquela né admiração de todo muno, parece assim que eles não estavam acreditando no que estavam vendo, não acreditavam na gente... Não acreditavam que existia índio (grifos nossos) (E22)

Os fragmentos confirmam que estes estudantes foram bem recebidos pela universidade e pelos colegas de turma. Trazem também um aspecto relevante a ser considerado: os estudantes indígenas são jovens que podem ser fenotipicamente muito parecidos com os habitantes regionais com quem convivem. Chegam ao ponto de serem invisíveis enquanto integrantes de coletividades etnicamente diferenciadas para a estrutura universitária que se inserem. (SOUZA LIMA; BARROSO-HOFFMANN, 2004)

Neste ponto volta à imagem mental carregada da questão: quem é ou não é índio? Por isso a admiração revelada pelos colegas de classe foi percebida pela estudante indígena E6. Assim, considera-se este, ser um aspecto delicado que as políticas de cotas e vagas suplementares trouxeram à consciência pública: o da identificação de quem é ou não é indígena, logo de quem tem ou não tem direitos diferenciados. A imagem que grande parte da população carrega é daquele índio idealizado, vivendo nas matas, seminu e protetor das florestas.

Entretanto, os estudantes indígenas na universidade, se diferem e muito de outros estudantes regionais que também são contemplados por cotas como: pobres, negros, estudantes de escola pública. A diferença reside em seu sistema de valores e de pensamento, em seus conhecimentos, em sua visão de mundo e em suas redes de parentesco e relacionamentos. Ou 
seja, os estudantes indígenas possuem uma identidade étnica diferenciada. Neste sentido Maher salienta que:

\begin{abstract}
A questão da identidade indígena, o "ser índio", remete, isto sim, a uma construção permanentemente refeita a depender da natureza das relações sociais que se estabelecem, ao longo do tempo, entre o índio e os outros sujeitos sociais e étnicos: tal construção busca: a) determinar especificidades que estabeleçam "fronteiras identificatórias" entre ele e um outro. b) obter o reconhecimento dos demais membros do grupo ao qual pertence, da legitimidade de sua pertinência a ele. (MAHER, 1996, p. 116)
\end{abstract}

Concordando com o posicionamento apresentado, nota-se que o índio constrói seu "modo de ser" na relação entre o tempo e no espaço social, com diferentes "outros". Assim, sua identidade passa a ser construída socio-historicamente, política, ideológica e em constante mutação. Neste sentido, ressalta-se que os estudantes indígenas na UNICENTRO possuem consciência acerca do peso do sistema de preconceitos que incide sobre eles - preconceitos estes que são diferentes dos afro-descendentes - em razão da trama de estereótipos e verdadeiras narrativas construídas ao seu redor.

Parte dos efeitos dessa trama é reduzir a rica diversidade de seus modos de viver a um ente único e genérico, que os brasileiros, negros, brancos, filhos de imigrantes, mulheres, supõem conhecer: o índio. Desta forma, quando perguntados se na recepção da UNICENTRO perceberam algum tipo de preconceito, responderam:

Ah fui bem recebida, mas no começo tava meio apreensiva né, porque não conhecia todo mundo né daí eu não sabia tipo como que eles iam, é... olhar pra mim né, tipo índia e tudo sabe, fiquei meio com medo assim porque tem lugares, aqui não foi o caso, mas tem lugares que tipo olham pra gente meio torto né, vai fazer alguma coisa já não gostam muito de chegar perto, por a gente ser índio né... (grifos nossos) (E13)

O relato apresenta que há preconceitos, que levam as pessoas, em formato de senso comum a considerarem as populações indígenas "distantes" da população branca no tempo e espaço, e ainda, relacionados à aparência do ser "índio".

Dito de outra forma, grande parte dos estudantes e professores universitários "brancos" quando solicitados a falar sobre os índios relataram que são os protetores das florestas (imagem do bom selvagem), são atrasados (porque possuem conhecimento milenar que não é provado cientificamente), são povos bárbaros, violentos, canibais e perigosos (representação esta ligada ao período colonial), são povos que estão distantes no tempo e no espaço (imagem esta representada nos livros de história), são povos que vivem na região amazônica e nas florestas (quando na verdade estão em todo território nacional) e aparência (vestimenta de penas e cocares). (MOTA, ASSIS, 2008 ; DIÁRIO DE PESQUISA, 2010). Sob o aspecto do "relacionamento interpessoal" e as "dificuldades enfrentadas" pelos estudantes indígenas na UNICENTRO, foram apontadas as seguintes colocações:

a) Relacionamento interpessoal: 
Então tipo a dificuldade é saber lidar assim com as pessoas do jeito que elas são mesmo né, acho que não pelo fato de eu ser índia né, mas um pouco é também porque daí tipo falou baixinho no ouvido do outro ali e olhou pra mim, eu já penso "eles estão falando alguma coisa de mim". (E13)

Observa-se que a estudante indígena E13, atribui a dificuldade de relacionamento interpessoal por não saber como se comportar em uma cultura diferente da sua. Ela justifica este aspecto pelo fato de ser índia e por várias dificuldades que encontrou durante seu processo de educação escolar formal, acredita que sempre as "pessoas estão falando dela ou sobre ela" (sic).

Após o término da gravação em áudio, esta estudante afirmou que para ela "é tudo muito difícil na universidade, porque ela não sabe como ou o que conversar com as jovens colegas de sua turma na universidade". Em relato, afirmou que "as jovens brancas, usam roupas da moda, falam de namorados, e não gostam muito de se enturmar com as índias". A estudante ressaltou ainda que "não faz muita questão de se relacionar com as moças da cidade, porque elas são muito oferecidas, e para os indígenas prevalece o respeito pela família". (DIÁRIO DE CAMPO, 2010)

b) Timidez:

Era muito tímida, eu era muito tímida, minha amiga... A princípio, no primeiro dia, no primeiro mês foi, sabe, tinha isso, tinha grupos, nós tinha um grupinho. Só que daí tinha uns que se afastavam da gente, tipo não queriam que a gente entrasse no grupo (E22)

Após o término da gravação em áudio, a estudante indígena entrevistadas alegou que a "timidez" apresentada na universidade não se reproduz na comunidade indígena. Ou seja, na comunidade ela não é tímida, conversa, se expressa, passeia e convive com o grupo. (DIÁRIO DE CAMPO, 2010)

Partindo das observações em campo, confirma-se que timidez que os indígenas sentem na universidade é porque convivem em um ambiente universitário cultural e social muito diferente do seu. A organização social indígena baseia-se na família extensa indicando um aspecto significativo que consiste na valorização das atividades coletivas. (MOTA; ASSIS, 2008)

Em contrapartida, na universidade que é um espaço eurocêntrico por natureza, observase haver um deslocamento de relações sociais vividas por estes indígenas. Neste ponto, cabe pensar que os estudantes indígenas, para permanecer no espaço universitário, necessitam saber converter-se a cultura local (universitária), comportando-se de maneira parecida com os outros estudantes, para que possam ser "aceitos". Esta conversão pode fomentar a timidez e o silenciamento nos atos de interlocução de fala.

c) Aparência/vestuário:

É a gente via que tinha, porque a gente ingressa em uma faculdade pública, a gente acha que é pessoas assim, pobrezinhas como a gente, porque a gente é né, a situação não é das melhores, então a gente pensa que é tudo no mesmo nível, mas chegando na sala de aula a gente depara que não é isso, porque ali dentro da sala de aula você não tá usando a roupa da moda, você não tá né... Então eles ve a simplicidade no teu olhar assim, no teu falar, no teu vestir, no 
teu andar, em tudo eles percebem, então eles fazem o grupinho deles ali e a gente que é mais pobre índio, fica isolada sempre né. (E21)

No fragmento apresentado por E21, observa-se um sentimento de exclusão pela maneira como ela se vestia. Ou seja, o fato de se vestir de maneira simples causava dificuldades em se relacionar com alguns colegas da turma, gerando um sentimento de isolamento. Vale salientar que nas relações cotidianas observa-se muito o julgamento de valor que as pessoas atribuem ao "outro" pautado na aparência (forma de vestir). Ou seja, impera nas relações sociais o "ter" e não o "ser". Para as culturas indígenas esta relação é contraditória, pois nestes povos a relação estabelecida é o "ser" antes do "ter". Os índios têm acesso ao mundo globalizado em suas aldeias, convivem com televisão, rádio, computadores, eletrodomésticos, mas suas relações sociais são pautadas em laços de parentesco, amizades, colaboração mútua entre vizinhos. Estes laços para os índios são mais importantes do que a forma de vestir. (MOTA; ASSIS, 2008 ; DIÁRIO DE CAMPO, 2010)

Em observações registradas, uma indígena já formada relatou: "na universidade eles (os colegas) olham muito se você está usando calça da moda, blusa da moda. Mas quando você pergunta sobre como é sua família, muitos respondem que 'é uma droga' que 'tem tudo, mas se sentem vazios'. Entre a gente (os índios) existem os problemas de toda ordem: violência, homens bebendo, fome, desnutrição, miséria, descaso das autoridades públicas etc, mas gente se ajuda, o índio não se sente vazio, ele é ajudado pelos vizinhos, por 'parentes' índios. Então, o que você veste não faz diferença, mas sim o que você é por dentro” (sic) (DIÁRIO DE CAMPO, 2010)

d) Língua:

Tinha bastante dificuldade, porque no conhecimento assim, que o índio ele tem uma maneira diferente de falar, a gente tem uma linguagem mais coloquial, mais simples né, e às vezes até eu não falava muito as coisas por vergonha de falar errado. Por vergonha, porque eu tinha medo de falar uma coisa assim que fosse (não entendi) né. (grifos nossos) (E23)

A estudante formada E23 apresenta um aspecto que considera uma dificuldade na UNICENTRO: a língua portuguesa. Esse aspecto pode ser explicado porque no Brasil há aproximadamente 180 línguas indígenas catalogadas por linguistas. Muitas destas línguas são eminentemente orais, havendo nos últimos 30 anos um movimento surgido nas próprias comunidades indígenas para grafá-las (BANIWA, 2006)

Entretanto, quando acessam a educação escolar indígena, grande parte dos professores, educadores e diretores não consideram a dificuldade que os povos indígenas apresentam na língua portuguesa. Para as populações indígenas, o português é uma língua estrangeira, o que causa dificuldades de aprendizagem desde a educação básica até a superior. Vygotsky afirma que:

É principalmente por meio da língua que produzimos nossas simbolizações, nossos pensamentos, nossas memórias. Cada língua produz abstrações que contribuem para a tradução de pensamentos e percepções. A língua está intimamente ligada com a forma de pensamento, de elaboração de abstrações, à maneira como cada grupo simboliza sua percepção no mundo. Língua e pensamento são manifestações humanas que estão intimamente interligadas. (VYGOSTKY, 2005, p. 67) 
Cabe destacar que, em sala de aula, os estudantes em geral, sejam pobres ou ricos, negros ou brancos, provenientes da escola pública ou privada, apresentam sérias dificuldades quanto à interlocução e aprendizagem em língua portuguesa. Essas dificuldades perpassam desde a semântica até a morfologia. Para completar, a variação da língua portuguesa está repleta de "estrangeirismos e gírias", o que aumenta o grau léxico de dificuldades. Desta forma, quando ampliado este problema para os demais "calouros" que ingressam na universidade, observa-se que um número significativo desses alunos chega com sérias dificuldades para compreender 0 discurso acadêmico mais elementar.

Com isso, infere-se que o calouro indígena e o não-indígena apresentam dificuldades de aprendizagem semelhantes em relação à sua iniciação em um universo no qual impera um tipo específico de discurso. Porém, as dificuldades dos indígenas tornam-se mais graves devido à sua especificidade sociocultural. Para as populações indígenas, utilizar a língua portuguesa como forma de comunicação nas escolas e universidades do Brasil, seria a mesma coisa que para um brasileiro utilizar a língua alemã, em um colégio da Alemanha, sem ter nenhum acesso a grafia e léxico. Em outras palavras, o brasileiro com certeza se sentiria um estrangeiro, isolado, perdido e com um nível de aprendizagem ínfimo, para não dizer "incapaz", produzindo simbolizações e abstrações negativas.

e) Por ser "cotista":

A gente sente né. Tipo assim exatamente, assim, pra mim assim não chegaram assim a falar, mas a gente sente assim no ar né, a gente vê e ouve quando falam mal dos cotistas. Então vejo que é pra nós índios, aí fica meio chato, meio difícil a relação né. (grifos nossos) (E6)

De acordo com os discursos, se nota que o estudante indígena afirmarou serem as relações sociais no meio universitário dificultadas quando se torna visível o acesso diferenciado. O fragmento apresenta ainda que este estudante possui a consciência que o acesso diferenciado por meio do vestibular especial de vagas suplementares não é um privilégio, mas uma necessidade e oportunidade de rompimento do ciclo de exclusão ao qual estiveram submetidos durante séculos no Brasil.

\section{CONSIDERAÇÕES FINAIS}

Durante a realização da pesquisa, entrevistando e acompanhando os estudantes indígenas da UNICENTRO e em Terras Indígenas, convivendo com os índios em seu cotidiano, pode-se compreender que a permanência/desistência do indígena na UNICENTRO é um processo social, que pode ser entendido como um "complexo fenômeno que envolve mudança não apenas de endereço (após cruzar a fronteira da aldeia), mas de toda uma série de contatos socioculturais do indivíduo, em todas as áreas da sua vida" (SARRIERA, 2005).

Dessa maneira, percebeu-se o porquê, muitas vezes, o "estresse psicológico" atinge os estudantes Guaranis e Kaingangs com a mudança de ambiente, ou seja, o relacionamento com um novo espaço, diferente do seu, e o relacionamento com professores e estudantes no espaço universitário que é totalmente diferente do que eles viviam antes de passarem no vestibular. Em outras palavras, percebeu-se como é difícil para o estudante indígena, adaptar-se com a mudança de ambiente, com novas formas de cultura, levando-o a desistência desta universidade. 
Ao considerar-se esse processo, constatou-se que o "projeto de inclusão dos indígenas na universidade" neste espaço secular e privilegiado, restringe-se apenas ao acesso. Ou seja, o efeito psicossocial gerado pela ideia falsa que um programa suplementar de vagas indígenas gera na sociedade é inteiramente distorsivo, pois cria uma falsa noção de que a sociedade estaria tornando-se mais igualitária e justa, quando de fato o que acontece é um "alargamento do grau de aceitação e conformismo" (FREITAS, 2005, p. 68) para com as diferentes e sutis formas de injustiça e exploração da vida cotidiana.

\section{REFERÊNCIAS}

1. AMARAL, W. R. do. As trajetórias dos estudantes indígenas nas universidades estaduais do Paraná: sujeitos e pertencimentos. Tese (Doutorado em Educação). Programa de PósGraduação em Educação. Universidade Federal do Paraná. Curitiba: UFPR, 2010.

2. BRASIL. Fundação Nacional do Índio. Portaria no 003/2002. Disponível em: www.funai.gov.br. Acesso em: 19/03/2009.

3. BRASIL. Fundação Nacional da Saúde. Demografia dos povos indígenas. Disponível em: http://www.funasa.gov.br/internet/desai/sistemaSiasiDemografialndigena.asp. Acesso em: 23 de agosto de 2010.

4. BANIWA, G. S. L. $\mathbf{O}$ índio brasileiro: o que você precisa saber sobre os povos indígenas no Brasil de hoje. Brasília: Ministério da Educação, Secretaria da Educação Continuada, Alfabetização e Diversidade: LACED/Museu Nacional, 2006.

5. CAJUEIRO, R. Os povos indígenas em instituições de ensino superior públicas federais e estaduais do Brasil: levantamento provisório de ações afirmativas e de licenciaturas interculturais. Disponível em: www.trilhasdeconhecimentos.etc.br Acesso em: 21 de fevereiro de 2009.

6. CAPELO, M. R. C. ; TOMMASINO, K. Conflitos e dilemas da juventude indígena do Paraná: escolarização e trabalho como acesso à modernidade. Trabalho apresentado no 30 은 Encontro Nacional de Estudos Rurais e Urbanos. USP: 28 a 30 de maio de 2003. Disponível em: www.usp.br Acesso em: 30 de agosto de 2008.

7. COSTA, O. Autonomia em Paulo Freire e educação indígena. Dissertação (Mestrado em Educação). Programa de Pós-Graduação em Educação. Universidade Regional de Blumenau. Blumenau: FURB, 2005.

8. D'ANGELIS, W. R. da. Contra da ditadura na escola: educação indígena e interculturalidade. Caderno Cedes, 49, 2000.

9. FREITAS, M. F. Q. de . (In)coerências entre práticas psicossocias em comunidade e projetos de transformação social: aproximações entre as Psicologias Sociais da Libertação e Comunitária. Psico (PUCRS. Impresso), Porto Alegre, v. vol 1, n.n. 1, p. 47-54, 2005.

10. FREITAS, M. F. Q. de. O psicólogo na comunidade: estudo da atuação de profissionais engajados em trabalhos comunitários. Dissertação (Mestrado em Psicologia Social). Programa de Pós-Graduação em Psicologia Social. Pontifícia Universidade Católica de São Paulo. São Paulo: PUCSP, 1986.

11. GOFFMAN, E. Estigma: notas sobre a manipulação da identidade deteriorada. 4.ed. Rio de Janeiro, Guanabara, 1988. 
12. MAHER, T. M. Ser professor, sendo índio: questões de linguagem e identidade. Tese (Doutorado em Linguística). Programa de Pós-Graduação em Linguística. Campinas: IEL/UNICAMP, 1996.

13. MARTINELLI, M. L. Pesquisa qualitativa: um instigante desafio. São Paulo: Editora Veras, 1999.

14. MOEHLECKE, S. Fronteiras da igualdade no ensino superior: excelência \& justiça racial. Tese (Doutorado em Educação). Programa de Pós-Graduação em Educação. Universidade de São Paulo. São Paulo: USP, 2004.

15. MOTA, L. T. ; Assis, V. S. de . Populações indígenas no Brasil: histórias, culturas e relações interculturais. Maringá: Eduem, 2008

16. NOVAK, M. S. J. Políticas da ação afirmativa: a inserção dos indígenas nas Universidades Públicas Paranaenses. Dissertação (Mestrado em Educação). Programa de Pós-Graduação em Educação. Universidade Estadual de Maringá. Maringá: UEM 2007.

17. OLIVEIRA, J. P. de. (Org). Indigenismo e territorialização: poderes, rotinas e saberes coloniais no Brasil contemporâneo. Rio de Janeiro: Contra Capa, 1998.

18. PARANÁ. Reserva 3 (três) vagas para serem disputadas entre os índios integrantes das sociedades indígenas paranaenses, nos vestibulares das universidades estaduais. Lei no 13.134 de 18/04/2001. Diário Oficial do Estado, Curitiba, n. 5969, 19 abr. 2001.

19. PAULINO, M. M. Povos indígenas e ações afirmativas: o caso do Paraná. Dissertação (Mestrado em Educação). Programa de Pós-Graduação em Educação. Universidade Federal do Rio de Janeiro. Rio de Janeiro: UFRJ, 2008.

20. RODRIGUES, I. ; WAWZYNAK, V. Inclusão e permanência no ensino superior público do Paraná: reflexões. Disponível em: www.acoesafirmativas.ufscar.br, 2006. Acesso em: 28 de março de 2010.

21. SARRIERA, J. C. (Org.) Psicologia comunitária: estudos atuais. Porto Alegre: Sulina, 2005.

22. SILVA. Z. L. Educação escolar indígena: por quê? e para quê? Monografia (Trabalho de Conclusão de Curso). Graduação em Pedagogia. Universidade Estácio de Sá. Rio de Janeiro, 2005.

23. SOUZA LIMA, A. C. de S.; BARROSO-HOFFMANN, M. (Orgs.). Seminário desafios para uma educação superior para os povos indígenas no Brasil: políticas públicas de ação afirmativa e direitos culturais diferenciados. Rio de Janeiro: Museu Nacional/LACED, 2004.

24. VYGOTSKY, L. S. Pensamento e linguagem. 5. ed. São Paulo: Martins Fontes, 2005. 